\title{
Adherence to treatment after CABG in terms of patients' personality
}

\author{
M. Iakovleva ${ }^{1}$, O. Shchelkova ${ }^{1}$, E. Lubinskaya ${ }^{2}$, and O. Nikolaeva ${ }^{2}$ \\ ${ }^{1}$ Saint Petersburg State University, Saint Petersburg, Russian Federation \\ ${ }^{2}$ Federal Almazov North-West Medical Research Centre, Saint Petersburg, Russian Federation
}

\begin{abstract}
The relevance of the problem is caused by the prevalence of cardiovascular diseases among the population, including coronary heart disease which requires surgical treatment, on the one hand, and low rates of treatment adherence among patients with chronic diseases, which reduce the effectiveness of the treatment and survival rates of patients, on the other hand. Patients after CABG were divided into groups according to the degree of their adherence to treatment and were examined by using the Big Five Questionnaire. Differences between the groups on the scales "conscientiousness" ( $p<0.001)$, "openness" $(p<0.001)$, "agreeableness" $(p<0.05)$, and "neuroticism" $(p<0.05)$ were revealed. The study showed that the psychological factors are relevant in the definition of adherence to treatment and patients' personality traits are potentially significant for the prediction of its degree among patients after CABG.

Key words: clinical psychology, $\mathrm{CABG}$, adherence to treatment, personality, Big Five Questionnaire.
\end{abstract}

\section{Introduction}

In 2014, the mortality from coronary heart disease (CHD) in the Russian Federation amounted to 492,303 people [1]. According to the European Society of Cardiology statistics, the mortality from CHD in Russia is one of the highest in Europe [2].

In this regard, nowadays the problem of treatment, rehabilitation and prevention of CHD (a disease which not only affects the quality of life of patients, but also leads to disability and death), is one of the most important and urgent problems in modern medicine $[3,4]$.

The data indicate that in patients with chronic diseases adherence to treatment does not exceed $50 \%[5,6]$. Poor adherence to treatment was also found in $1 / 3$ of patients with psychosomatic diseases, more often among patients suffering from ulcer disease and coronary heart disease (40\%) [7].

Despite the presence of numerous data on the socio-demographic and clinical factors affecting the degree of patients' adherence to prescribed therapeutic measures (e.g., the impact of the disease severity [8,9], the dosing regimen [10], patients' sex and age [11-13], as well as their social status and education level [14]), the question of the influence of patients' personality on their therapeutic behaviour, and the question of influence of certain psychological characteristics on patients' degree of adherence, remain open. 
Some researchers believe that this influence is insignificant and do not acknowledge the importance of patients' personality in determining adherence to treatment $[15,16]$, but physicians' clinical experience and the increasing interest of researchers in this issue [17] indicate the opposite.

Many studies have been carried out, trying to propose a unified classification of factors affecting the adherence to treatment $[18,19]$, as well as many meta-analyzes, considering the available data and making an attempt to systematize the accumulated material [20-22].

There is no "psychological factors of adherence" group in these classifications. A group named "factors related to the patient" usually corresponds to the patients' age and race, but not their personality features, characteristics of coping behaviour, cognitive functioning, mindsets or their beliefs. Taking into account all the aforesaid it seems relevant to investigate the psychological characteristics of patients in relation to their adherence to long-term treatment.

Among patients who underwent $\mathrm{CABG}$, poor adherence to restorative treatment and supportive care is particularly dangerous, as it reduces the efficiency of surgery and the health outcomes, leading to disease relapses and increasing the treatment costs [5, 23].

The social consequences (impacts) of this phenomenon are also significant: the patient creates an idea of the physician's incompetence and the senselessness of further treatment, and the doctor creates an image of a "hopeless patient" [24].

Thus, the objective of this study was formulated. The aim of the research was to study the psychological factors of adherence to treatment (more specifically - features of the personality structure) among patients suffering from coronary heart disease, who underwent CABG.

\section{Materials and methods}

\subsection{Materials}

A total of 100 patients suffering from coronary heart disease (CHD) were examined in this study. The sample consisted of 82 men $(82 \%$, their average age was 58.96 years (SD = $8.68)$, at the age between 44 and 79 years), and 18 women (18\%, their average age was 63.94 years $(\mathrm{SD}=8.54)$, with age between 51 and 83 years $)$.

About $40 \%$ of patients suffered CHD for more than 6 years, $23 \%-3-6$ years, $17 \%-1-$ 3 years, and about $20 \%$ of patients were diagnosed with CHD recently, less than one year before the necessity of surgery emerged. Of the patients, $68 \%$ suffered one or more myocardial infarction by the time of the surgery. All the studied patients underwent coronary bypass grafting $(\mathrm{CABG})$ at the Federal Almazov North-West Medical Research Centre (Saint Petersburg, Russian Federation).

The following concomitant diseases were observed more often (without CVD, in descending order) among patients in the studied group: diseases of the gastrointestinal tract (chronic gastritis, gastric ulcer, duodenal ulcer), diseases of the pulmonary system (chronic bronchitis, chronic obstructive pulmonary disease), diseases of the urinary system (urolithiasis, cystitis), diseases of the locomotor system (arthritis, scoliosis of different regions of the spine, degenerative-dystrophic damage of the spine), endocrine diseases.

\subsection{Methods}

We conducted a complex study of patients' demographic, socioeconomic, clinical and psychological characteristics. The following set of methods was used: a detailed study of medical records of each patient, a structured interview with patients which consisted of a 
wide range of questions about their family, job, social activity, habits and mindsets, and a psychometric technique - the "Big Five Questionnaire" [25], adapted and standardized on a Russian sample [26].

Patients' adherence to treatment was assessed using an expert method, performed by an interdisciplinary team of experts (cardiologists and clinical psychologists). Several aspects were considered when determining the degree of patients' adherence: their adherence to the drug therapy and adherence to the recommended lifestyle changes, such as keeping to a diet, following the recommended level of physical activity, controlling blood pressure indicators and weight, reducing alcohol consumption and quitting smoking. Assessment of adherence to treatment was performed not earlier than 3 months after CABG, to insure patients' return to normal independent life and adaptation to their new health state and lifestyle.

\section{Results and discussion}

\subsection{Results}

Initially, the psychological characteristics of the studied patients were analyzed in accordance with the division into two groups - adherent and non-adherent to treatment (Table 1).

Table 1. Average scores on the scales of the Big Five Questionnaire in two groups of patients.

\begin{tabular}{|c|c|c|c|}
\hline $\begin{array}{c}\text { Factors of personality } \\
\text { traits (scales of the Big } \\
\text { Five Questionnaire) }\end{array}$ & $\begin{array}{c}\text { Adherent to } \\
\text { therapy (n= 52) } \\
\text { M (SD) }\end{array}$ & $\begin{array}{c}\text { Non-adherent to } \\
\text { therapy (n=48) } \\
\text { M (SD) }\end{array}$ & $p$ \\
\hline \hline Extraversion & $26.33(0.67)$ & $26.29(0.82)$ & 0.973 \\
\hline Conscientiousness & $31.92(0.62)$ & $27.31(0.81)$ & 0.000 \\
\hline Agreeableness & $32.29(0.64)$ & $29.65(0.92)$ & 0.019 \\
\hline Neuroticism & $24.48(0.87)$ & $27.54(0.90)$ & 0.016 \\
\hline Openness & $27.46(0.80)$ & $21.00(0.95)$ & 0.000 \\
\hline
\end{tabular}

It has already been shown that such a division is justified and allows determining significant differences between the patients on the characteristics of their personality [27]. The study of the patients' structure of personality using the technique "Big Five Questionnaire" revealed the individual psychological characteristics which are typical for the studied groups of patients.

Thus, it was found that patients who do not follow health recommendations showed significantly lower values on several scales of the questionnaire than adherent patients. These patients proved to have statistically significant lower values on the scale of "Conscientiousness" (meaning they are more careless, forgetful and irresponsible) ( $p<$ 0.001 ), as well as on the scale of "Openness" (meaning they have a lack of imagination, artistry and personal resources) $(p<0.001)$. These patients also showed statistically significant differences from the adherent to treatment group on the scale "Agreeableness": patients with poor adherence to treatment are characterized by lower values on this scale, which means they are more unfriendly and less trusting and cooperative $(p<0.05)$.

On the other hand, adherent to treatment patients have lower values on the scale "Neuroticism" $(p<0.05)$ in comparison with the second group, it means that patients with a higher degree of adherence are more anxious, moody, emotional and unstable. 
The issue of the process of division of patients into groups itself, the possibility of pole division of patients suffering from CHD, into two polar groups - adherent and non-adherent to treatment - remains relevant. This brings up the question of the impact that may cause a more differentiated division into groups based on the degree of adherence to the treatment on the results obtained with respect to the psychological characteristics of patients.

Upon further study, the sample was divided more differentially into the following three groups:

1. Group I: included those patients who received the highest values in all aspects of adherence, i.e. complying with doctors' recommendations on the admission of drugs (dosage, frequency and so on) (adherent to pharmacological therapy), performing control (and, if required, decrease) of their weight, dieting (following the designated by the doctor restrictions on various foods), following the recommended level of physical activity, performing the recommended exercise and giving up harmful habits completely or largely giving up smoking, reducing alcohol consumption (adherent to non-pharmacological therapy). It can be concluded that patients from this group are truly adherent to the treatment and have the most favourable prognosis with respect to following the recommendations of doctors. For brevity, this group will be henceforth designated "adherent to treatment patients".

2. Group II: consisted of patients, non-adherent to treatment in all aspects of adherence; they do not follow (or follow at a minimal degree) the doctors' recommendations on pharmacological treatment, do not perform monitoring of blood pressure, diet and exercise regime. This group has the least favorable indicators in terms of adherence to treatment. The second group of patients can be named "non-adherent to treatment patients".

3. Group III: included the patients who implemented the recommendations only for drug therapy (regularly taking prescribed medications) and were monitored regularly by a cardiologist, but who did not follow the recommendations on diet and refusal of harmful habits, or performing lifestyle changes. This group can be described as "relatively (partly) adherent patients" because, despite the fact that adherence to pharmacotherapy is an essential aspect of the therapy effectiveness, in isolation from other prescribed measures it is insufficient. Despite this circumstance, the prognosis in respect of adherence to treatment in this group of patients is significantly more favorable than that of patients from the second group.

In the course of the study the three groups of patients described above were compared once more on their psychological characteristics using analysis of variance (ANOVA) (Table 2).

Table 2. Average scores on the scales of the Big Five Questionnaire in three groups of patients.

\begin{tabular}{|c|c|c|c|c|c|}
\hline $\begin{array}{c}\text { Factors of } \\
\text { personality traits } \\
\text { (scales of the Big } \\
\text { Five Questionnaire) }\end{array}$ & $\begin{array}{c}\text { Group I } \\
(n=45) \\
M(\mathrm{SD})\end{array}$ & $\begin{array}{c}\text { Group II } \\
(n=27) \\
M(\mathrm{SD})\end{array}$ & $\begin{array}{c}\text { Group III } \\
(n=28) \\
M(\mathrm{SD})\end{array}$ & $\begin{array}{c}\text { Differences } \\
\text { between } \\
\text { groups }\end{array}$ & $p$ \\
\hline \hline Extraversion & $\begin{array}{c}26.42 \\
(5.20)\end{array}$ & $\begin{array}{c}26.13 \\
(5.40)\end{array}$ & $\begin{array}{c}26.64 \\
(5.36)\end{array}$ & - & $p>0.1$ \\
\hline Conscientiousness & $\begin{array}{l}31.53 \\
(0.73)\end{array}$ & $\begin{array}{c}27.87 \\
(0.87)\end{array}$ & $\begin{array}{c}28.80 \\
(1.34)\end{array}$ & I*II & 0.030 \\
\hline Agreeableness & $\begin{array}{c}32.62 \\
(0.72)\end{array}$ & $\begin{array}{c}29.48 \\
(1.20)\end{array}$ & $\begin{array}{c}30.92 \\
(1.16)\end{array}$ & $\mathrm{I}^{*} \mathrm{II}$ & 0.077 \\
\hline Neuroticism & $\begin{array}{l}24.56 \\
(1.00)\end{array}$ & $\begin{array}{c}28.96 \\
(1.34)\end{array}$ & $\begin{array}{c}25.64 \\
(1.06)\end{array}$ & $\mathrm{I}^{*} \mathrm{II}$ & 0.028 \\
\hline Openness & $\begin{array}{c}25.76 \\
(6.28)\end{array}$ & $\begin{array}{c}22.22 \\
(7.01)\end{array}$ & $\begin{array}{c}24.28 \\
(7.23)\end{array}$ & - & $p>0.1$ \\
\hline
\end{tabular}


The analysis of average values on the questionnaire scales showed that there were statistically significant difference in several personality features among adherent, nonadherent and relatively (partly) adherent to treatment patients who underwent coronary bypass surgery.

Adherent to treatment patients (group I) have higher scores on the scale "Conscientiousness" $(p<0.05)$ and lower scores on the scale "Neuroticism" $(p<0.05)$ compared with patients with a poor level of adherence (group II). Difference between adherent and non-adherent patients on a statistical tendency level has also been identified on the scale "Agreeableness" $(p<0.1)$ - patients from group I tend to be more trusting and cooperative.

That is, the division of patients into three groups according to their adherence to therapy (that also seems more logical from the clinical point of view) is also productive in regard of research. However, it should be noted that, as data in Table 2 indicates, the major difference has been found between the groups I and II, i.e. between groups "adherent to treatment patients" and "non-adherent to treatment patients". This fact testifies the validity and sufficiency of the initial division into two groups, carried out at the first stage of the research.

\subsection{Discussion}

Patients with different degrees of adherence to treatment were found to be significantly different on several personality characteristics: adherent patients are characterized by a higher willingness to agreement and cooperation. These data are confirmed by other researchers in other medical fields. For example, it was determined that the lack of readiness to cooperate and oppositional behaviours have a negative effect on adherence to treatment also in patients with cystic fibrosis [28].

On the other hand, the examined in this study no adherent to treatment patients significantly differ by lower personal resources and lower responsibility, conscientiousness and self-discipline. Similar tendencies are marked in other studies: for example, Stilley et al. found that higher scores on the factor "conscientiousness" in patients are significant predictors of high adherence to hypolipidemic therapy [29]. Later, these data was confirmed also on a sample of patients suffering from other diseases. Karamanidou et al. in their study showed the negative effect of hostility and low levels of self-consciousness on adherence to drug therapy in patients with renal disease [30]. Carelessness and poor skills of self-organization in conjunction with laziness are considered to be a negative factor affecting adherence to therapy also in patients suffering from tuberculosis [31].

All the above mentioned confirms the researchers' high interest in regard to the patients' personality in the context of their adherence to treatment, and allows to assert that patients' personality features play an important role in determining the level of adherence to both - pharmacological and non-drug - treatment among patients with different diseases, including patients with CHD after CABG surgery.

Other psychological characteristics of patients that are related to their personality features and may affect the therapeutic behaviour, such as their coping behaviour (coping strategies and personality coping resources), system of values, beliefs (including beliefs about health and the disease), and the patients' attitude towards the disease, also require further studies. 


\section{Conclusions}

Patients' characteristics of personality have a prognostic value in relation to the degree of adherence to treatment after CABG surgery: good self-organisation skills, responsibility, willingness to cooperate and the aspiration to self-development and personal growth have a positive effect, calmness and emotional stability - have negative effect. Thus, it was found that both strategies of dividing patients into either two or three groups according to their adherence to therapy is promising in terms of scientific investigation and reveals significant difference in the psychological characteristics (personality features in particular) of patients with different degrees of adherence to treatment.

Summarizing all the above mentioned, it is essential to indicate the importance of the psychological factors in the definition of adherence to treatment. The obtained empirical data on the patients' psychological characteristics contribute to increase in the efficacy of therapy by providing professional psychological support to patients who underwent CABG and making psycho corrective programs for no adherent to treatment patients.

\section{References}

1. Estestvennoe dvizhenie naseleniya Rossiyskoy Federatsii v 2014 godu: byulleten' [Vital Statistics of the Russian Federation in 2014: Bulletin] (Statisticheskiy byulleten' Publ., Moscow, 2015) (In Russ.)

2. N. Townsend, L. Wilson, P. Bhatnagar, K. Wickramasinghe, M. Rayner, M. Nichols, Eur Heart J. 37(42), 3232-3245 (2016)

3. World Health Organization, Prevention of cardiovascular disease: guidelines for assessment and management of total cardiovascular risk (WHO, Geneva, 2007)

4. L.A. Bockeria, M.M. Alshibaya, N.G. Bendeliani, S.Ph. Nikonov, K.V. Krymov, The Bulletin of A.N. Bakoulev Scientific Center for Cardiovascular Surgery of Russian Academy of Medical Sciences. Cardiovascular diseases. 13(1), 38-47 (2012) (In Russ.)

5. World Health Organization, Adherence to long-term therapies, evidence for action (WHO, Geneva, 2003)

6. B. Hagström, B. Mattsson, I.M. Rost, R.K. Gunnarsson, Fam Pract. 21(1), 46-50 (2004)

7. I.A. Novikova, V.V. Popov, Med. psihol. Ross. 6(35), 9 (2015) (In Russ.)

8. J. Leong, A. Molassiotis, H. Marsh, Clin Effect in Nurs. 8(1), 26-38 (2004)

9. S. Choi-Kwon, S.U. Kwon, J.S. Kim, Eur Neurol. 54(4), 204-211 (2005)

10. A.J. Claxton, J.A. Cramer, C. Pierce, Clin Ther. 23, 1296-1310 (2001)

11. M.C. Wong, W.W. Tam, C.S. Cheung, E.L. Tong, A.C. Sek, N.T. Cheung, S. Leeder, S. Griffiths, Int J Cardiol. 167(4), 1438-1442 (2013)

12. K. Krueger, L. Botermann, S.G. Schorr, N. Griese-Mammen, U. Laufs, M. Schulz, Int J Cardiol. 184, 728-735 (2015)

13. M.W. Schoen, R.G. Tabak, J. Salas, J.F. Scherrer, F.R. Buckhold, Am J Cardiol. 117(1), 48-53 (2016)

14. P. Theofilou, H. Panagiotaki, Oncol Rev. 6(1), e5 (2012)

15. D. Hevey, H.M. McGee, J. Horgan, Psychosom Med. 69, 793-797 (2007)

16. V. Fuster, Rev Esp Cardiol. 65(Suppl 2), 10-16 (2012)

17. L.A. Phillips, H. Leventhal, E.A. Leventhal, Psychol Health. 28(10), 1135-1151 (2013)

18. T. Mathes, T. Jaschinski, D. Pieper, Arch Public Health. 72(1), 37 (2014)

19. A.F. Yap, T. Thirumoorthy, Y.H. Kwan, Geriatr Gerontol Int. 16(10), 1093-1101 (2015) 
20. J. Jin, G.E. Sklar, V. Min Sen Oh, S. Chuen Li, Ther Clin Risk Manag. 4(1), 269$286(2008)$

21. F. Alsolami, X.-Yu. Hou, I. Correa-Velez, Clin Med Diagnostic. 2(4), 27-32 (2012)

22. P. Kardas, P. Lewek, M. Matyjaszczyk, Front. Pharmacol. 4, 91 (2013)

23. L. Osterberg, T. Blaschke, N Engl J Med. 353(5), 487-497 (2005)

24. D.S. Danilov, Psychiatry and Psychopharmacotherapy (P.B. Gannushkin Journal), 10(1), 13-20 (2008) (In Russ.)

25. L.A. Pervin, O.P. John, Personality: Theory and research (7th ed.) (John Wiley \& Sons, New York, 1997)

26. D.P. Yanichev, Cognitive aspects of self-perception of personality traits in patients with neurotic and neurosis-like symptoms (Saint-Petersburg State University, SaintPetersburg, 2006)

27. M.V. Iakovleva, O.Y. Shchelkova, C.I. Lubinskaya, J Cardiol Clin Res. 4(1), 1055 (2016)

28. J.R. Weiner, E.L. Toy, P. Sacco, M.S. Duh, Expert Opin. Pharmacother. 9(5), 751766 (2008)

29. C.S. Stilley, S. Sereika, M.F. Muldoon, C.M. Ryan, J. Dunbar-Jacob, Ann Behav Med. 27(2), 117-124 (2004)

30. C. Karamanidou, J. Clatworthy, J. Weinman, R. Horne, BMC Nephrol. 9, 2 (2008)

31. S.A. Munro, S.A. Lewin, H.J. Smith, M.E. Engel, A. Fretheim, J. Volmink, PLoS Med. 4(7), e238 (2007) 
